This document is confidential and is proprietary to the American Chemical Society and its authors. Do not copy or disclose without written permission. If you have received this item in error, notify the sender and delete all copies.

\title{
Tuning Bandgap of p-type Cu2Zn(Sn, Ge)(S, Se)4 Semiconductor Thin Films via Aqueous Polymer-Assisted Deposition
}

\begin{tabular}{|r|l|}
\hline Journal: & ACS Applied Materials \& Interfaces \\
\hline Manuscript ID & am-2016-13683b.R1 \\
\hline Manuscript Type: & Article \\
\hline Date Submitted by the Author: & 06-Dec-2016 \\
\hline Complete List of Authors: & $\begin{array}{l}\text { Yi, Qinghua; Soochow University, } \\
\text { Wu, Jiang; University College London, Electronic and Electrical Engineering } \\
\text { Zhao, Jie; Soochow University, } \\
\text { Wang, Hao; Soochow University, } \\
\text { Hu, Jiapeng; Soochow University } \\
\text { Dai, Xiao; Soochow University, } \\
\text { Zou, Guifu; Soochow University, }\end{array}$ \\
\hline \hline
\end{tabular}

SCHOLARONE

Manuscripts 


\title{
Tuning Bandgap of p-type $\mathrm{Cu}_{2} \mathrm{Zn}(\mathrm{Sn}, \mathrm{Ge})(\mathrm{S}, \mathrm{Se})_{4}$
}

\section{Semiconductor Thin Films via Aqueous Polymer-}

\section{Assisted Deposition}

\author{
Qinghua Yi, ${ }^{\ddagger}$ Jiang Wu, $\mathcal{S}$ Jie Zhao, ${ }^{\ddagger}$ Hao Wang, ${ }^{\ddagger}$ Jiapeng Hu, ${ }^{\ddagger}$ Xiao Dai, ${ }^{\ddagger}$ Guifu Zou ${ }^{\ddagger}, *$ \\ ${ }^{\ddagger}$ College of Physics, Optoelectronics and Energy \& Collaborative Innovation Center of Suzhou \\ Nano Science and Technology, Soochow University, Suzhou 215006, China \\ $\S$ Department of Electronic and Electrical Engineering, University College London, London \\ WC1E 7JE, UK
}




\begin{abstract}
Bandgap engineering of kesterite $\mathrm{Cu}_{2} \mathrm{Zn}(\mathrm{Sn}, \mathrm{Ge})(\mathrm{S}, \mathrm{Se})_{4}$ with well-controlled stoichiometric composition plays a critical role in sustainable inorganic photovoltaics. Herein, a cost-effective and reproducible aqueous solution-based polymer-assisted deposition approach is developed to grow p-type $\mathrm{Cu}_{2} \mathrm{Zn}(\mathrm{Sn}, \mathrm{Ge})(\mathrm{S}, \mathrm{Se})_{4}$ thin films with tunable bandgap. The bandgap of $\mathrm{Cu}_{2} \mathrm{Zn}(\mathrm{Sn}, \mathrm{Ge})(\mathrm{S}, \mathrm{Se})_{4}$ thin films can be tuned within the range $1.05 \mathrm{eV}-1.95 \mathrm{eV}$ using the aqueous polymer-assisted deposition by accurately controlling the elemental compositions. One of the as-grown $\mathrm{Cu}_{2} \mathrm{Zn}(\mathrm{Sn}, \mathrm{Ge})(\mathrm{S}, \mathrm{Se})_{4}$ thin films exhibits a hall coefficient of $+137 \mathrm{~cm}^{3} / \mathrm{C}$. The resistivity, concentration and carrier mobility of the $\mathrm{Cu}_{2} \mathrm{ZnSn}(\mathrm{S}, \mathrm{Se})_{4}$ thin film are $3.17 \mathrm{ohm} \cdot \mathrm{cm}$, $4.5 \times 10^{16} \mathrm{~cm}^{-3}$, and $43 \mathrm{~cm}^{2} / \mathrm{V} \cdot \mathrm{S}$ at room temperature, respectively. Moreover, the $\mathrm{Cu}_{2} \mathrm{ZnSn}(\mathrm{S}$, $\mathrm{Se})_{4}$ thin film when used as an active layer in a solar cell leads to a power conversion efficiency of $3.55 \%$. The facile growth of $\mathrm{Cu}_{2} \mathrm{Zn}(\mathrm{Sn}, \mathrm{Ge})(\mathrm{S}, \mathrm{Se})_{4}$ thin films in an aqueous system, instead of organic solvents, provides great promise as an environmental-friendly platform to fabricate a variety of single/multi metal chalcogenides for the thin film industry and solution-processed photovoltaic devices.
\end{abstract}

KEYWORDS: CZTGeSSe, solution processing, bandgap tunable, polymer-assisted deposition, solar cells

\title{
INTRODUCTION
}

$\mathrm{Cu}_{2} \mathrm{Zn}(\mathrm{Sn}, \mathrm{Ge})(\mathrm{S}, \mathrm{Se})_{4}(\mathrm{CZTGSSe})$ is one of the most promising $p$-type semiconductors in the optoelectronics field due to its low toxicity, cost-efficiency, abundance, high light absorption coefficient and direct bandgap. It has been widely applied to different fields including photocatalysis, ${ }^{1,2}$ photovoltaics, ${ }^{3-6}$ and biomedicines. ${ }^{7}$ More importantly, the CZTGSSe has a tunable bandgap depending on the compositions of $\mathrm{Sn}, \mathrm{Ge}, \mathrm{S}$, and Se elements. ${ }^{8,9}$ It is well known that chemical solution synthesis approaches are effective in precisely controlling the 
composition of the multicomponent material. ${ }^{10}$ Many recent efforts have been devoted to growing CZTGSSe thin films by chemical solution processes. For example, Mitzi et al. have fabricated $\mathrm{Cu}_{2} \mathrm{Zn}(\mathrm{Sn}, \mathrm{Ge}) \mathrm{S}_{4}$ (CZTGS) thin films by a pure-hydrazine solution approach. ${ }^{9}$ The Moon group used a nanocrystal ink approach to grow CZTGS thin films. ${ }^{11}$ These solutionprocessed films show great promise as effective light absorber layers in photovoltaic devices. However, harmful/toxic solvents, ${ }^{12}$ complex synthesis, and tedious post-purification ${ }^{13,14}$ limit the use of these methods to grow CZTGSSe thin films in a viable manner for industry applications. Therefore, it is highly demanded to develop an alternative environmental-friendly solution route for synthesis of bandgap tunable CZTGSSe thin films.

Water has been well recognized as an ideal and green solvent. However, easily-hydrolyzed metal ions (e.g. Sn, Ge, etc.) are difficult to form a stable solution in water. ${ }^{15,16}$ Moreover, it is hard to control the metal ion concentration of the aqueous precursor solution, which often results in non-stoichiometric growth of the compound thin film. Here, we present a stable metal-ion aqueous system, comprising a homogeneous metal-polymer complex solution, to grow single/multiple metal sulfide/selenide thin films. A water-soluble polymer is used to stabilize the metal ions in precursor solution and facilitate the film coating. Specifically, the metal ions (nitrates salt, chloride salt) coordinate with lone-pair electrons of the nitrogen atoms in the polymer preventing hydrolysis of metal ions and hence forming stable metal-polymer complexes. $^{17,18}$ Meanwhile, the non-coordinated anions or cations are easily removed by filtration processes to prepare a homogeneous precursor solution. By carefully adjusting the concentration of the $\mathrm{Cu}, \mathrm{Zn}, \mathrm{Sn}$, and Ge precursors, the final aqueous solution can provide the desired stoichiometric mixture at the molecular level. The resulting stable and homogeneous solution ensures precisely control of the stoichiometry and spatial uniformity for the films. 
Adjustment of the stoichiometry results in different bandgaps for the CZTGSSe films ranging from $1.05 \mathrm{eV}$ to $1.95 \mathrm{eV}$. In this work, as one typical example of CZTGSSe thin films, CZTSSe film prepared by the polymer-assisted aqueous method is demonstrated with a hall coefficient of $+137 \mathrm{~cm}^{3} / \mathrm{C}$ and carrier mobility of $43 \mathrm{~cm}^{2} / \mathrm{V} \cdot \mathrm{S}$ at room temperature, respectively. Moreover, the CZTSSe thin film, when used as the active layer in an inorganic solar cell, yields a power conversion efficiency of $3.55 \%$.

\section{RESULTS AND DISCUSSION}

The schematic diagram of precursor preparation process and annealing process are shown in Figure 1. To investigate the thermal decomposition of the precursor thin film, we utilize TG/DTA 7300 to trace the thermal behaviors of the mixed metal precursor solution under an argon atmosphere. Figure 2(a) shows that the sample begins to decompose at $200{ }^{\circ} \mathrm{C}$ and stops at around $450{ }^{\circ} \mathrm{C}$. This suggests that the polymer is almost completely decomposed and that CZTGSSe thin films may be obtained above $450{ }^{\circ} \mathrm{C}$. The mass spectroscopy data from a typical decomposition process (Figure S1) shows that the polymer decomposes into a molecular gas during the thermal treatment. The small gaseous molecules are swept away by the gas flow leaving behind pure metal atoms, which results in the growth of high-quality thin films. It is worth noting that the crystallinity of the resultant thin films is influenced by the annealing process and temperature. X-ray diffraction patterns (XRD) (Figure 2(b) and Figure 2(c)) were used to identify the crystal structures of the CZTGSSe thin films. All the peaks in the XRD data from samples A, C, E can be assigned to kesterite CZTSe (JCPDS: 52-0868), CZTS (JCPDS: 260575) and CZGS (JCPDS: 78-781). The prominent peaks at ca. $28.5^{\circ}, 33.0^{\circ}, 47.3^{\circ}$, and $56.2^{\circ}$ can be indexed to the (112) (200) (220), and (312) orientations for CZTGSSe. It is interesting to see that all the major peaks have regular shifts from samples A to E. Figure 2(c) shows the trend of 
the peak corresponding to the (112) peak. The shifts can be attributed to changing atomic mass. By replacing the lighter (smaller) S atom $(1.84 \AA$ ) with heavier (larger) Se atom $(1.98 \AA)$ in a CZTS lattice after the selenization process, the diffraction peak in XRD pattern of sample B shows a distinct shift to lower (two-theta) angles compared with sample $\mathrm{C}$ due to the corresponding expansion in the unit cell. The $\mathrm{Se} /(\mathrm{Se}+\mathrm{S})$ ratio can be calculated to be 0.32 based on the shift of the two-theta angles. A similar trend in XRD pattern for sample D is found when some $\mathrm{Sn}$ atoms are substituted by $\mathrm{Ge}$ atoms. In this case the ratio $\mathrm{Ge} /(\mathrm{Ge}+\mathrm{Sn})$ is 0.41 . Apart from the shifts, no unidentified peaks or peaks from secondary phases were observed in any of the XRD spectra. Based on the above analyses, samples A, B, C, D and E in Figure 2(b) correspond to the following thin films: $\mathrm{Cu}_{2} \mathrm{ZnSnSe}_{4}$ (CZTSe), $\mathrm{Cu}_{2} \mathrm{ZnSn}\left(\mathrm{S}, \mathrm{Se}_{4}\right)$ (CZTSSe), $\mathrm{Cu}_{2} \mathrm{ZnSnS}_{4}$ (CZTS), $\mathrm{Cu}_{2} \mathrm{Zn}(\mathrm{Sn}, \mathrm{Ge}) \mathrm{S}_{4}(\mathrm{CZTGS})$ and $\mathrm{Cu}_{2} \mathrm{ZnGeS}_{4}(\mathrm{CZGS})$, respectively. As is well known, XRD patterns are insufficient to confirm the phase purity of CZTGSSe structures due to similar diffraction peaks of binary and ternary chalcogenides. ${ }^{19}$ Here, Raman spectroscopy is employed to confirm the purity of the thin films. For the Raman spectroscopy of such thin films (Figure 2(d)), major characteristic peaks appear at $286 \mathrm{~cm}^{-1}$ and $336 \mathrm{~cm}^{-1}$ for sample C, corresponding to CZTS as previously reported. ${ }^{20-23}$ No evidence of other possible binary phases $\left(\mathrm{Cu}_{2} \mathrm{~S}, \mathrm{ZnS}, \mathrm{Cu}_{2} \mathrm{SnS}_{3}\right)$ appear in the Raman spectra. ${ }^{24}$ For sample A, the major peak shifts to 194 $\mathrm{cm}^{-1}$ which is consistent with the reported value for CZTSe. ${ }^{25,26}$ It is found that the Raman spectra show a systematic shift to a lower wavenumber as one substitutes the smaller $\mathrm{S}$ atoms with larger Se atoms. On the other hand, the major peaks are shifted to larger wavenumber along when replacing Sn atoms with Ge atoms. While the Sn atoms are completely substituted by Ge for sample E, the two strong peaks at $360 \mathrm{~cm}^{-1}$ and $291 \mathrm{~cm}^{-1}$ can be assigned to CZGS thin 
films. ${ }^{27}$ Thus, in combination, the XRD and Raman spectroscopic data confirm high purity of CZTGSSe thin films are grown by our aqueous solution approach.

The valence states of the constituent elements about CZTSSe and CZTGS are investigated by X-ray Photoelectron Spectroscopy (XPS). Figure 3(a) is the full spectrum of CZTSSe thin film, it indicates that the thin film contains $\mathrm{Cu}, \mathrm{Zn}, \mathrm{Sn}, \mathrm{S}, \mathrm{Se}$, and $\mathrm{C}$ elements. Figure 3(b-f) are the high-resolution spectra of $\mathrm{Cu} 2 \mathrm{p}, \mathrm{Zn} 2 \mathrm{p}, \mathrm{Sn} 3 \mathrm{~d}, \mathrm{~S} 2 \mathrm{p}$, and Se 2p. As can be seen, the binding energy value of $\mathrm{Cu} 2 \mathrm{p}$ are $951.60 \mathrm{eV}$ and $931.82 \mathrm{eV}$ with a peak splitting of $19.78 \mathrm{eV}$, which is correspond to the $\mathrm{Cu}^{+}$. It can be illustrated that the $\mathrm{Cu}^{2+}$ has been reduced to $\mathrm{Cu}^{+}$during the progress. The peaks show binding energy value of $\mathrm{Zn} 2 \mathrm{p}$ at $1044.62 \mathrm{eV}$ and $1021.62 \mathrm{eV}$ with a separation of $23.0 \mathrm{eV}$, which is consistent with divalent $\mathrm{Zn}^{2+}$. The spectrum of $\mathrm{Sn} 3 \mathrm{~d}$ exhibits two characteristic peaks at $494.72 \mathrm{eV}$ and $486.22 \mathrm{eV}$ with a split orbit of $8.5 \mathrm{eV}$. It suggests that the $\mathrm{Sn}^{2+}$ have been oxidized to $\mathrm{Sn}^{4+}$ during the grown progress. This shows the $\mathrm{Cu}^{2+}$ phase is reduced to $\mathrm{Cu}^{+}$while $\mathrm{Sn}^{2+}$ is oxidized to $\mathrm{Sn}^{4+}$ during the growth progress. ${ }^{8,28}$ Meanwhile, the spectra of $\mathrm{S}$ can be fitted to two peaks which are assigned to $\mathrm{S} 2 \mathrm{p}$. The peaks at $55.3 \mathrm{and} 54.6 \mathrm{eV}$ are corresponding to the Se $2 \mathrm{p}$. Therefore, these results are in line with the reported values of the binding energy of the elements forming CZTSSe, further confirming the phase purity of the synthesized CZTSSe. Furthermore, the XPS spectra (Figure S2) of CZTGS thin film were exhibited, which illustrated the pure CZTGS was grown.

The surface morphology and layer properties of the deposited CZTSSe thin films were also investigated. Figure 4(a, c) and $\mathbf{4}(\mathbf{b}, \mathbf{d})$ show the film has a dense and uniform structure, which is free of cracks. The average grain size is about $85 \mathrm{~nm}$. Cross-sectional SEM studies show the thin film has a homogeneous thickness and a sharp interface between the film and the substrate. The thickness of the films is about $2 \mu \mathrm{m}$ after spin-coating 5 times. It is worth noting that the 
thickness of the film could be adjusted with different spin-coating repetition times. Elemental mapping (Figure S3 (a-g)) of the CZTSSe film is helpful to understand the elemental distribution. The different colors (Figure S3 (a-g)) of yellow, green, blue, red, pink, light blue and white represent $\mathrm{Cu}, \mathrm{Zn}, \mathrm{Sn}, \mathrm{S}, \mathrm{Se}, \mathrm{C}$ and $\mathrm{O}$, respectively. The uniform colors suggest that the five major elements $(\mathrm{Cu}, \mathrm{Zn}, \mathrm{Sn}, \mathrm{S}, \mathrm{Se})$ are homogeneously distributed in the film. Upon combining all five elemental maps in Figure S3 (h), the uniform colorful image further confirms the compositional purity of the film, which is consistent with the results obtained from XRD and Raman spectroscopy. It is noting that the EDX data in Table S1 shows the CZTGSSe thin films have a copper-poor and zinc-rich conditions. ${ }^{29}$ Some literatures report that the copper-poor and zinc-rich films tend to have better device performance applying to inorganic solar cells. ${ }^{30}$

The bandgap of the CZTGSSe thin films can be tuned by varying an elemental component. Usually, there are four components ( $\mathrm{Sn}, \mathrm{Ge}, \mathrm{S}$, and $\mathrm{Se}$ ) influencing the bandgap of CZTGSSe. The bandgap of CZTSSe can be tuned between $1.0 \mathrm{eV}$ to $1.5 \mathrm{eV}$ by adjusting the ratio of $\mathrm{Se} /(\mathrm{Se}+\mathrm{S}) .{ }^{8,31,32}$ Similarly, the bandgap of CZTGS can be manipulated between $1.5 \mathrm{eV}$ to 2.25 eV by adjusting of the $\mathrm{Sn}$ and Ge compositions. ${ }^{14,33,34}$ The bandgap of the CZTGSSe thin films prepared in this work can be calculated through their UV-Vis absorption spectra (Figure S4). The relationship of the optical absorption coefficient $(\alpha)$ and optical bandgap $\left(E_{g}\right)$ of the thin films is given by the following formula (1):

$$
(A h v)=A\left(h v-E_{g}\right)^{m}
$$

Where $\mathrm{A}$ is a constant and the exponent value $(m)$ is $1 / 2$ for a direct band transition. Therefore, the $E_{g}$ of $\mathrm{Cu}_{2} \mathrm{Zn}(\mathrm{Sn}, \mathrm{Ge})(\mathrm{S}, \mathrm{Se})_{4}$ with direct band transitions can be calculated by formula (2):

$$
(A h v)^{2}=A\left(h v-E_{g}\right)
$$


The optical bandgap is obtained by extrapolating the linear part of the plot $(a h v)^{2}$ versus $h v$ (Figure 5(a)). The result indicates that the bandgap of CZTS thin films is $1.55 \mathrm{eV}$. As the $\mathrm{S}$ atoms are substituted by $\mathrm{Se}$, the bandgap decreases to $1.05 \mathrm{eV}$. For $\mathrm{Se} /(\mathrm{Se}+\mathrm{S})$ of 0.32 , the bandgap of CZTSSe obtained from the plot $(a h v)^{2}$ versus $h v$ is $1.35 \mathrm{eV}$. Meanwhile, the bandgap of $\mathrm{CZTSSe}(\mathrm{Se} /(\mathrm{Se}+\mathrm{S})=\mathrm{x})$ can be modeled by vegard's law using the following equation:

$$
E_{g}(x)=(1-x) E_{g}(C Z T S)+x E_{g}(C Z T S e)-b x(1-x)
$$

Where $\mathrm{b}$ is a constant relating to the nonlinear relationship between the bandgap and the ratio of $\mathrm{Se} /(\mathrm{Se}+\mathrm{S})$. According to the calculation, the bandgap of CZTSSe, is about $1.37 \mathrm{eV}$, which is in good agreement with the experimental value. Similarly, the bandgap of CZTGS films increases as the Ge content is increased (by replacing $\mathrm{Sn}$ atoms). For a ratio of $\mathrm{Ge} /(\mathrm{Ge}+\mathrm{Sn})=0.41$, the bandgap of the CZTGS film extracted from the absorption plot is $1.67 \mathrm{eV}$, in close agreement to the theoretical value of $1.71 \mathrm{eV}$. When Ge completely replaces $\mathrm{Sn}$, the bandgap of CZGS is estimated to be $1.95 \mathrm{eV}$. In short, the bandgap of CZTGSSe can be adjusted from 1.05 to $1.95 \mathrm{eV}$ by controlling the $\mathrm{Sn}, \mathrm{Ge}, \mathrm{S}$, and Se compositions.

The electrical properties of the thin films were evaluated by a physical properties measurement system (PPMS). An evaluation of the typical CZTSSe thin film was carried out using a four-probe van der Pauw method. As shown in Figure 5(b), the film exhibits a resistivity of $3.17 \Omega \mathrm{cm}$ at room temperature. The resistivity gradually increases with decreasing temperature, suggesting semiconducting behavior. The Hall coefficient $R_{H}$ is $+137 \mathrm{~cm}^{3} / \mathrm{C}$ indicating the CZTSSe film to be $p$-type. The carrier concentration $\left(n_{\mathrm{s}}\right)$ and Hall mobility $(\mu)$ can be calculated, according to the following equations (4) and (5),

$$
n_{S}=1 / e R_{H}
$$




$$
\mu=R_{H} / \rho
$$

Where $n_{\mathrm{s}}$ is carrier concentration, $e$ is the electron charge, $R_{H}$ is Hall coefficient, $\mu$ is Hall mobility, and $\rho$ is resistivity. The carrier concentration and Hall mobility are measured to be $4.5 \times 10^{16} \mathrm{~cm}^{-3}$ and $43 \mathrm{~cm}^{2} \mathrm{~V}^{-1} \mathrm{~s}^{-1}$ at room temperature, respectively. The carrier concentration is similar to the other reports by Liu et al. $\left(3.9 \times 10^{16} \mathrm{~cm}^{-3}\right)$ and Scragg et al. $\left(1.7 \times 10^{16} \mathrm{~cm}^{-3}\right),{ }^{35,36}$ but lower than Nakazawa et al. $\left(10^{18}-10^{19} \mathrm{~cm}^{-3}\right)$ found. ${ }^{37}$ The mobility of holes is higher than most of the other works. Liu et al. reported the mobility of CZTS film is $30 \mathrm{~cm}^{2} \mathrm{~V}^{-1} \mathrm{~s}^{-1}$ and Tanaka et al. reported the hall mobility is about $6.0 \mathrm{~cm}^{2} \mathrm{~V}^{-1} \mathrm{~s}^{-1} \cdot 35,38$ This suggests that our grown p-type CZTSSe films are of high quality and promising for optoelectronics applications.

With a suitable bandgap and good mobility of hole, the p-type CZTSSe thin film as an absorptive layer was assessed for its suitability in a solar cell. A typical solar cell was been fabricated with $\mathrm{SLG} / \mathrm{Mo} / \mathrm{CZTSSe} / \mathrm{CdS} / \mathrm{ZnO} / \mathrm{ITO} / \mathrm{Ag}$ layers. The physical image of the solar cell is shown in Figure S5. The device (Figure 6(a)) displays a $J_{s c}$ of $28.75 \mathrm{~mA} / \mathrm{cm}^{2}, \mathrm{~V}_{\mathrm{oc}}$ of $0.39 \mathrm{~V}$ and FF of 0.317 , yielding a conversion efficiency $\sim 3.55 \%$. Though the conversion efficiency is mediocre, it is comparable to solar cells that employ organic solvents. ${ }^{39,40}$ Such as H. W. Hillhouse group reported $4.1 \%$ conversion efficiency with dimethyl sulfoxide solvent and Y. Yang et al. reported $1.2 \%$ by single-component precursor with hydrazine. ${ }^{41,42}$ Figure 6(b) shows EQE spectrum of the solar cell and exhibits a broad absorption from 350 to $980 \mathrm{~nm}$. Without any optimization of the device, a high EQE over $60 \%(\sim 660 \mathrm{~nm})$ has been achieved. The bandgap of the CZTSSe film in a solar cell was calculated to be $1.35 \mathrm{eV}$ (inset of Figure 6(b)) which is in good agreement with the value estimated from the absorption spectrum. To analyze the device structure, the cross-section image of the device was investigated by SEM (Figure 6(c)). The 
device includes Mo substrate, CZTSSe layer, and CdS/ZnO/In-doped $\mathrm{SnO}_{2}(\mathrm{ITO})$ layer. Surprising to find that CZTSSe layer consists a small grain layer about $1200 \mathrm{~nm}$ and a large layer about $300 \mathrm{~nm}$. The cross-section morphology of the CZTSSe layer is different from that grown on a quartz substrate. The different morphology is resulting from the annealing process. The CZTSSe grown on quartz is annealed from the room-temperature at a rate of $5{ }^{\circ} \mathrm{C} / \mathrm{min}$ to $520^{\circ} \mathrm{C}$ and maintained at $520^{\circ} \mathrm{C}$ for $20 \mathrm{~min}$, while the CZTSSe active layer in the solar cell is annealed by a rapid thermal process (RTP). It indicates that the large grain CZTSSe layer is grown during the RTP. The interface between the small grain layer and the large grain layer may be not an ideal structure, and the small grain CZTSSe layer will hindrance the electrons' and holes' transportation. ${ }^{43}$ Thereby the small grain CZTSSe layer will affect the performance of the device. To analyze the element distribution in the device, the SEM-EDAX-Line (Figure 6 (d)) is measured at the cross-section of the device according to the arrows direction as Figure 6 (c) shown. The $\mathrm{Cu}, \mathrm{Zn}$, Sn atoms show a uniform distribution in the active layer. However, the Se atom percent show a higher ratio in the large grain layer than the small grain layer and there is a carbon content in the small grain CZTSSe layer from the carbon spectrum. Therefore a carbon residue is impeding the formation of the large CZTSSe particles, resulting a high series resistance and restricting the transport of photo-generated carriers and forming recombination, thereby deteriorate to the performance of the device. A lot of methods have been proposed to improve the quality of the CZTSSe activity layer, the small grain layer is still existence yet. So the continued optimization of the CZTSSe activity layer is a significant challenge in the future.

\section{CONCLUSIONS}

In summary, we report an environmental-friendly aqueous solution-based polymer assisted deposition approach to growing high-quality $\mathrm{Cu}_{2} \mathrm{Zn}(\mathrm{Sn}, \mathrm{Ge})(\mathrm{S}, \mathrm{Se})_{4}(\mathrm{CZTGSSe})$ thin films. The 
experimental results demonstrated CZTGSSe films can be easily tailored to fabricate with accurately controlled elemental compositions. Furthermore, the corresponding bandgaps of CZTGSSe thin films are readily tuned from $1.05 \mathrm{eV}$ to $1.95 \mathrm{eV}$ by changing the $\mathrm{Sn}, \mathrm{Ge}, \mathrm{S}$, and Se composition in the aqueous precursor solution. A representative CZTSSe film exhibits good electrical properties along with optical properties and high charge mobility. Carrier transport measurements also indicated that a hall coefficient of $+137 \mathrm{~cm}^{3} / \mathrm{C} \mathrm{s}$ was achieved on one of our as-grown $\mathrm{Cu}_{2} \mathrm{Zn}(\mathrm{Sn}, \mathrm{Ge})(\mathrm{S}, \mathrm{Se})_{4}$ thin films. Meanwhile, other performance metrics including the resistivity, concentration and carrier mobility of the $\mathrm{Cu}_{2} \mathrm{ZnSn}(\mathrm{S}, \mathrm{Se})_{4}$ thin film are meeting practical applications with values of $3.17 \mathrm{ohm} \cdot \mathrm{cm}, 4.5 \times 10^{16} \mathrm{~cm}^{-3}$ and $43 \mathrm{~cm}^{2} / \mathrm{V} \cdot \mathrm{S}$ at room temperature, respectively. Importantly, the $\mathrm{Cu}_{2} \mathrm{ZnSn}(\mathrm{S}, \mathrm{Se})_{4}$ thin film, used as an active layer in a solar cell, yields a power conversion efficiency of $3.55 \%$. Therefore, the feasible growth of $\mathrm{Cu}_{2} \mathrm{Zn}(\mathrm{Sn}, \mathrm{Ge})(\mathrm{S}, \mathrm{Se})_{4}$ thin films via an environmental benign aqueous system provides an effective pathway to fabricate a variety of single/multi metal films for solar energy applications and other solution-processed optoelectronic devices.

\section{ACKNOWLEDGMENTS}

We gratefully acknowledge the support from "973 Program---the National Basic Research Program of China" Special Funds for the Chief Young Scientist (2015CB358600), the Excellent Young Scholar Fund from National Natural Science Foundation of China (21422103), Jiangsu Fund for Distinguished Young Scientist (BK20140010), the Priority Academic Program Development of Jiangsu Higher Education Institutions (PAPD), and Jiangsu Scientific and Technological Innovation Team (2013).

Supporting Information. The detailed experimental section, the decomposed progress of a typical precursor solution; the mass spectrum of the decomposed products; XPS analysis, 
UV-Vis spectra, element ratio table of CZTGSSe thin films and the structure of the solar cell are included in the supporting information.

\section{AUTHOR INFORMATION}

\section{Corresponding Author}

*Email: zouguifu@suda.edu.cn

\section{Author Contributions}

The manuscript was written through contributions of all authors. All authors have given approval to the final version of the manuscript.

\section{Notes}

The authors declare no competing financial interest.

\section{FIGURES}

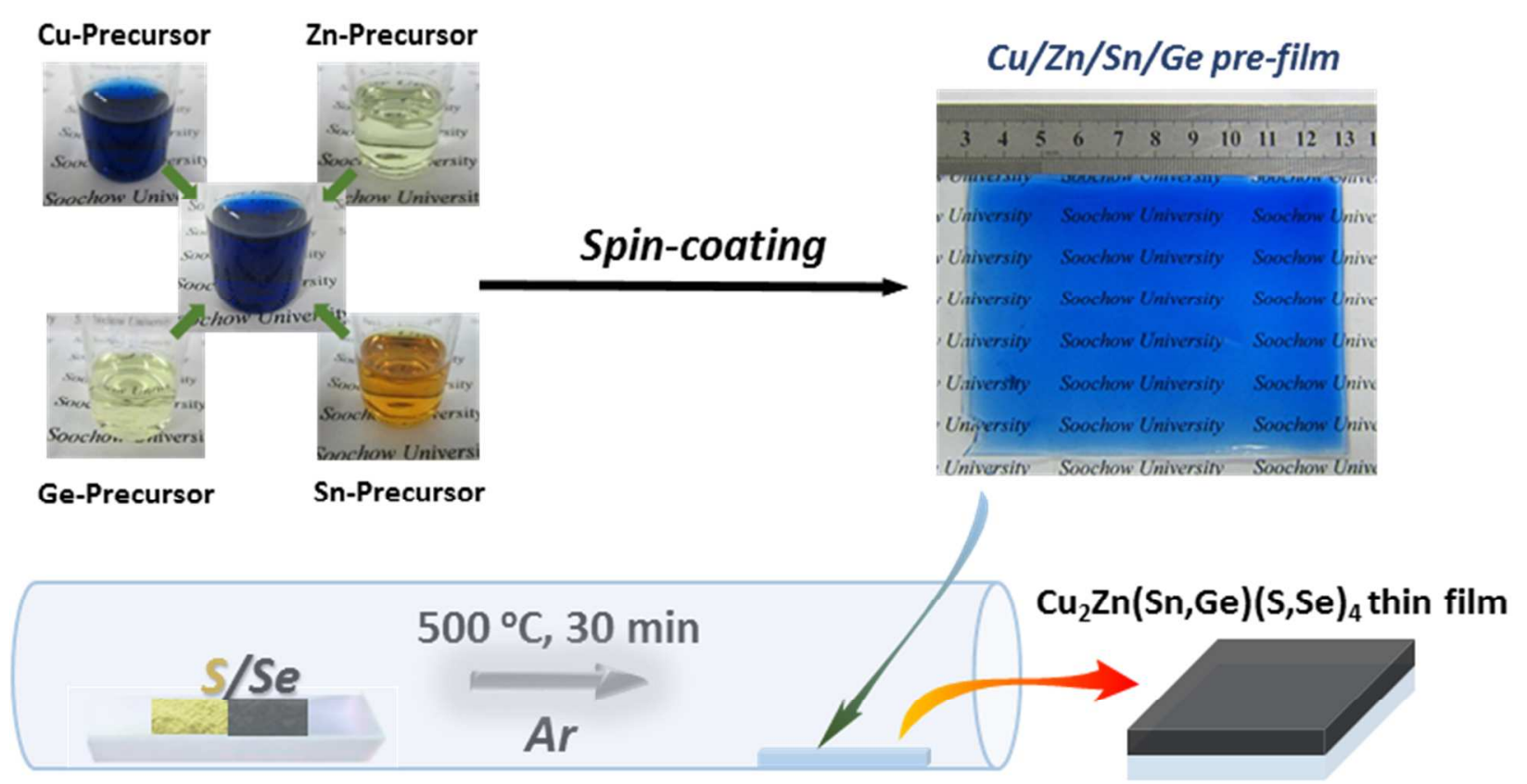


Figure 1. schematic illustration of precursor preparation progress and thin film annealing progress.
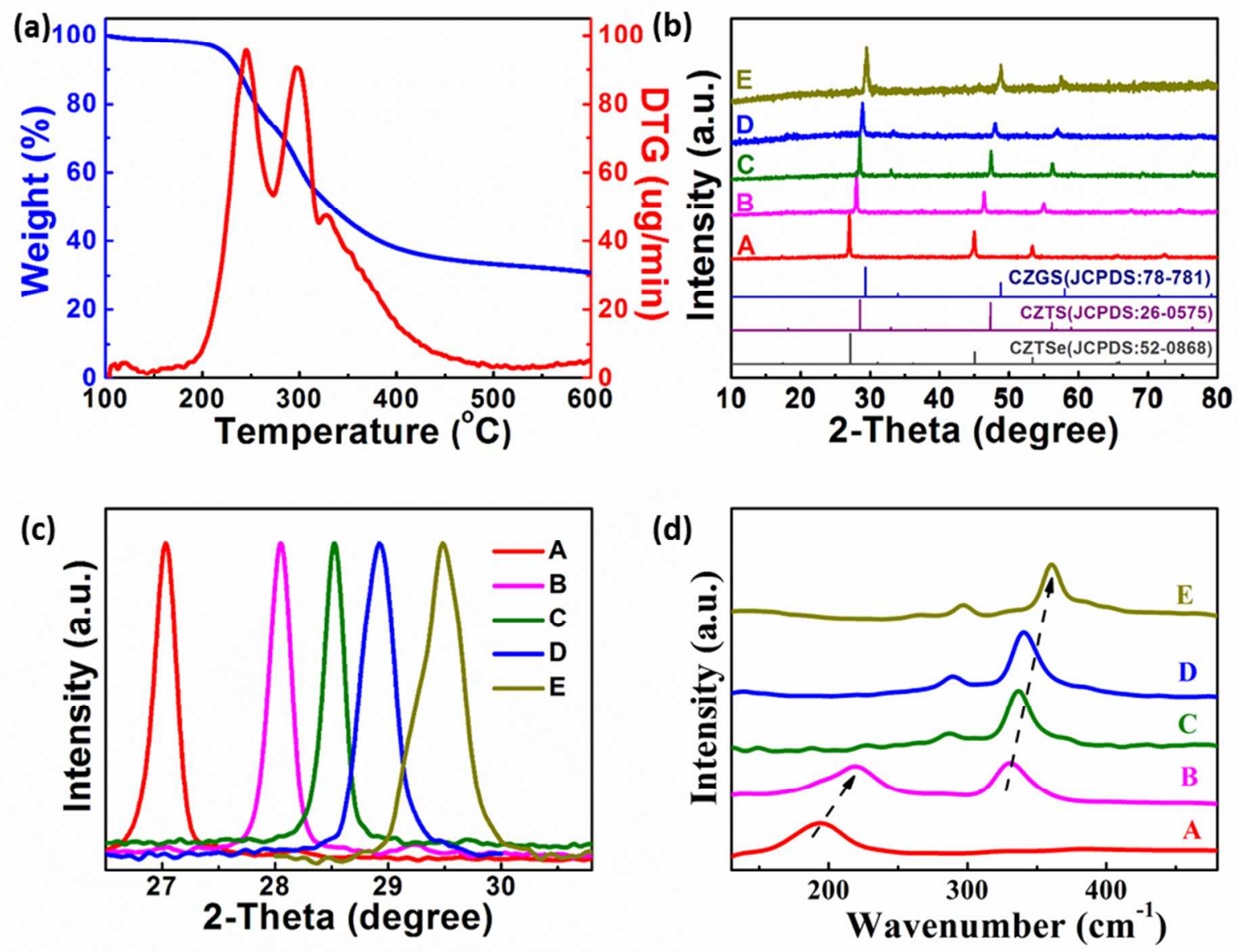

Figure 2. (a) Thermal gravimetric analysis (TGA) curve of $\mathrm{CuZn}(\mathrm{Sn}, \mathrm{Ge})$ precursor solution. (b) XRD patterns of CZTGSSe thin films. (c) The normalized (112) diffraction peak of all samples. (d) Raman spectra of CZTGSSe thin films (A: CZTSe, B: CZTSSe, C: CZTS, D: CZTGS, E: CZGS). 

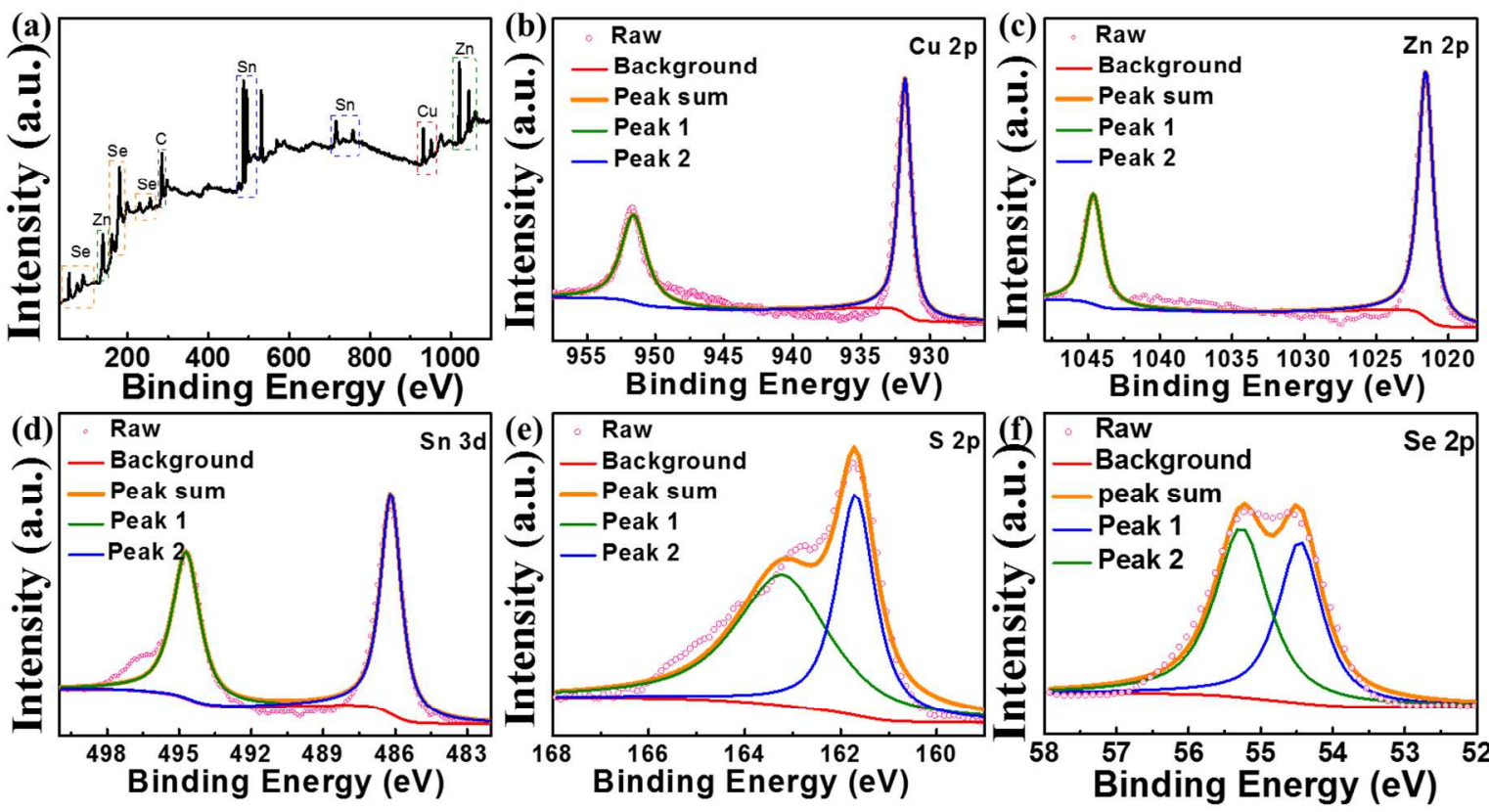

Figure 3. The XPS analysis of the CZTSSe thin films (a) full spectra, (b)Cu $2 p$ core level, (c)Zn $2 p$ core level,(d) Sn 3d core level, (e) S 2p core level and (f) Se 2p core level.

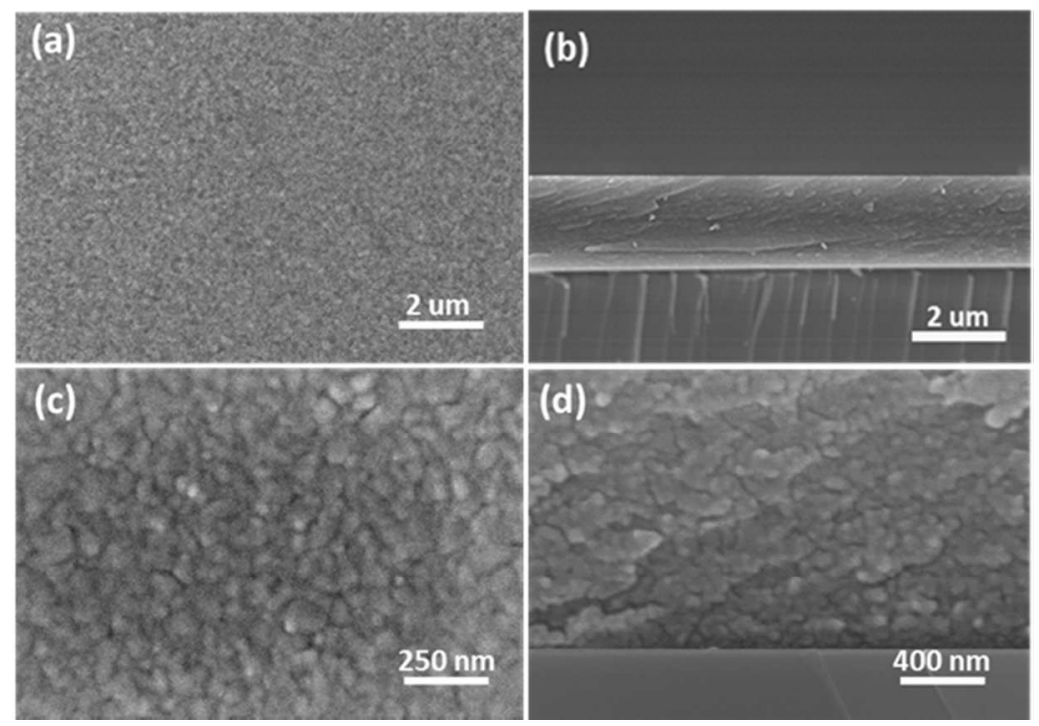

Figure 4. (a, c) Top-view and (b, d) Cross-section images of CZTSSe thin films. 
(a)

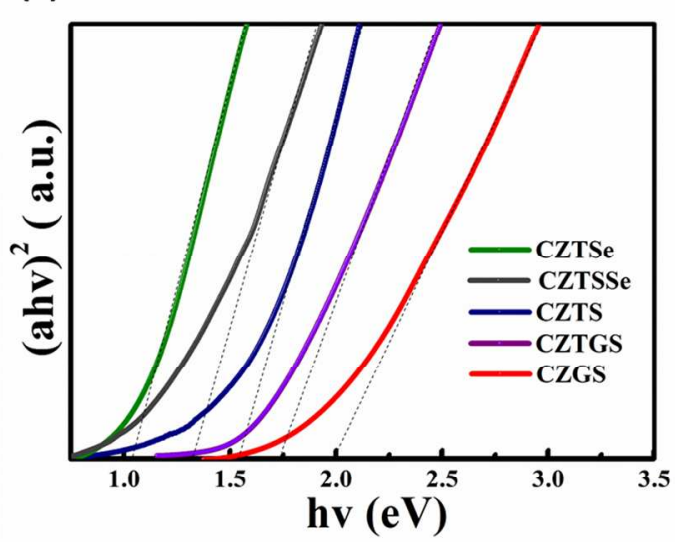

(b)

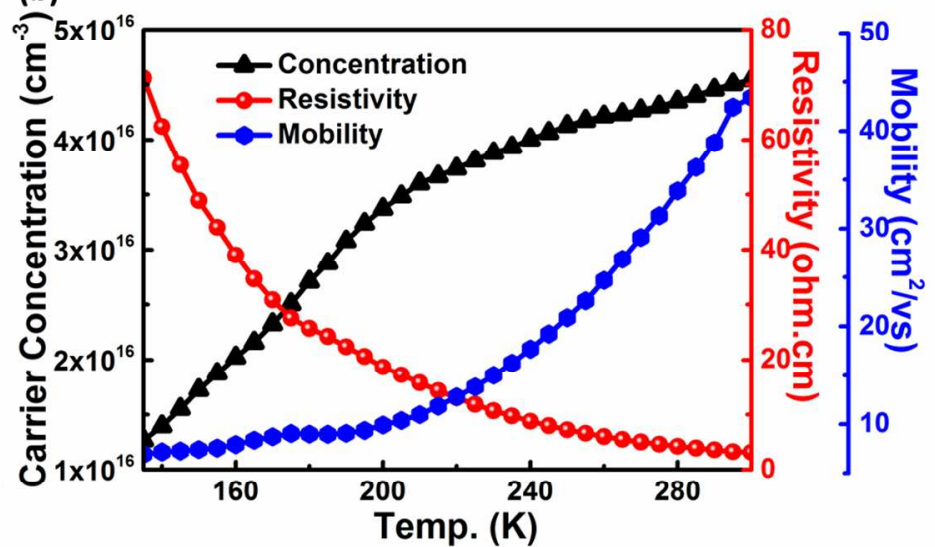

Figure 5. (a) The band gap values of obtained $\mathrm{Cu}_{2} \mathrm{Zn}(\mathrm{Sn}, \mathrm{Ge})(\mathrm{S}, \mathrm{Se})_{4}$ thin films, evaluated from the plots of $(a h v)^{2}$ vs. $h v$. (b) The temperature dependence of resistivity, concentration and mobility of the CZTSSe thin films, respectively. 

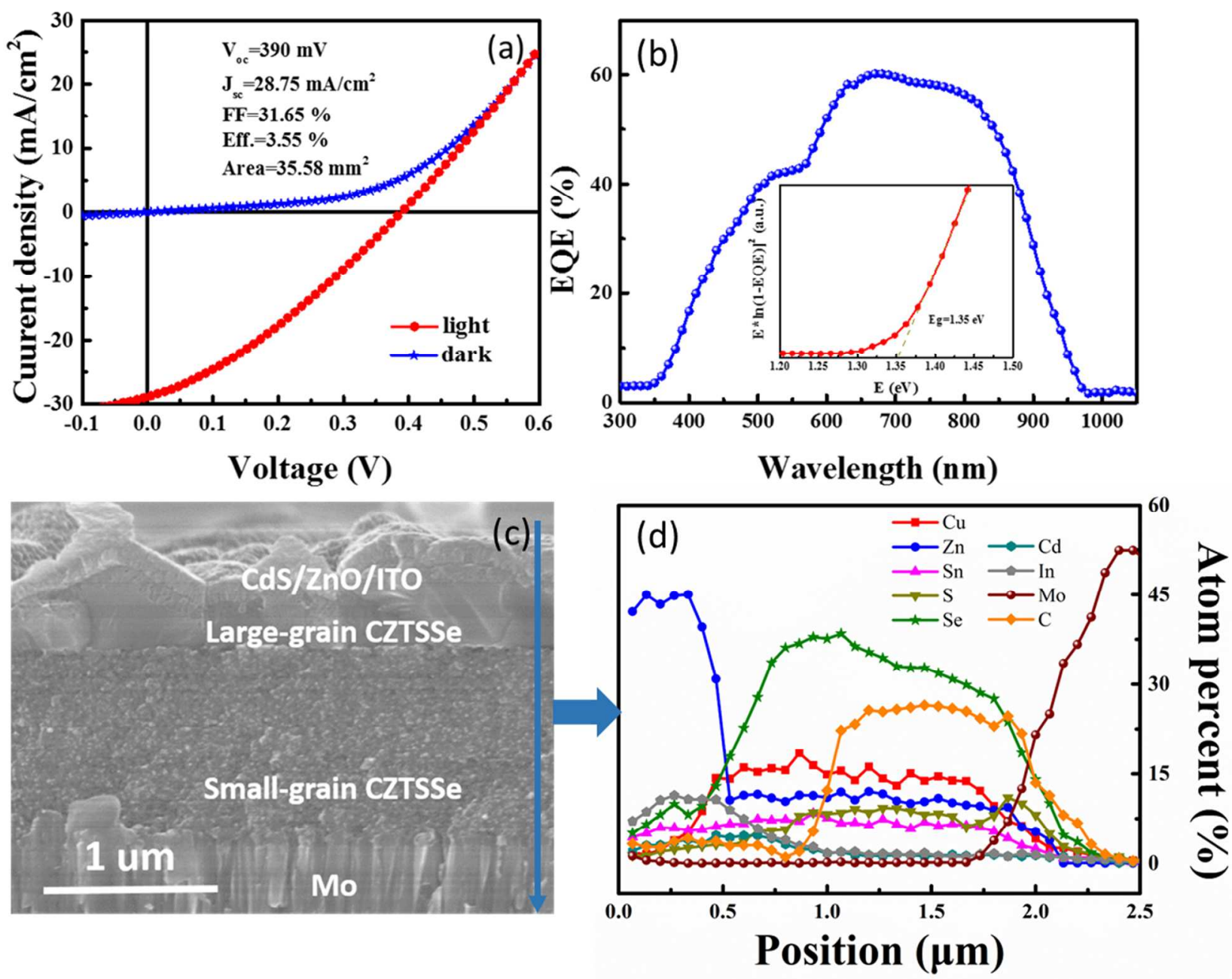

Figure 6. (a) The current density-voltage $(J-V)$ characteristics, (b) EQE plot of the CZTSSe solar cell, respectively. Inset, the bandgap is calculated by $\left[\mathrm{E}^{*} \ln (1-\mathrm{EQE})\right]^{2}$ vs. E curve. Cell area: $\left.0.3558 \mathrm{~cm}^{2}\right]$, (c) the cross-section SEM image of a CZTSSe solar cell, (d) the compositional distributions of CZTSSe solar cell was tested via SEM-EDAX-line scan. 


\section{REFERENCES}

(1) Yu, X.; Shavel, A.; An, X.; Luo, Z.; Ibanez, M.; Cabot, A. $\mathrm{Cu}_{2} \mathrm{ZnSnS}_{4}-\mathrm{Pt}$ and $\mathrm{Cu}_{2} \mathrm{ZnSnS}_{4}-\mathrm{Au}$ Heterostructured Nanoparticles for Photocatalytic Water Splitting and Pollutant Degradation. J. Am. Chem. Soc. 2014, 136, 9236-9239.

(2) Xin, X.; He, M.; Han, W.; Jung, J.; Lin, Z. Low-cost Copper Zinc Tin Sulfide Counter Electrodes for High-efficiency Dye-sensitized solar cells. Angew. Chem. Int. Ed. 2011, 50, 11739-11742.

(3) Todorov, T. K.; Tang, J.; Bag, S.; Gunawan, O.; Gokmen, T.; Zhu, Y.; Mitzi, D. B. Beyond $11 \%$ Efficiency: Characteristics of State-of-the-Art $\mathrm{Cu}_{2} \mathrm{ZnSn}(\mathrm{S}, \mathrm{Se})_{4}$ Solar Cells. Adv. Energy Mater. 2013, 3, 34-38.

(4) Mitzi, D. B.; Yuan, M.; Liu, W.; Kellock, A. J.; Chey, S. J.; Deline, V.; Schrott, A. G. A High-Efficiency Solution-Deposited Thin-Film Photovoltaic Device. Adv. Mater. 2008, 20, 3657-3662.

(5) Yang, W.; Duan, H. S.; Bob, B.; Zhou, H.; Lei, B.; Chung, C. H.; Li, S. H.; Hou, W. W.; Yang, Y. Novel Solution Processing of High-efficiency Earthabundant $\mathrm{Cu}_{2} \mathrm{ZnSn}(\mathrm{S}, \mathrm{Se})_{4}$ solar cells. Adv. Mater. 2012, 24, 6323-6329.

(6) Siebentritt, S.; Schorr, S. Kesterites-A Challenging Material for Solar Cells. Prog. Photovolt: Res. Appl. 2012, 20, 512-519.

(7) Panthani, M. G.; Khan, T. A.; Reid, D. K.; Hellebusch, D. J.; Rasch, M. R.; Maynard, J. A.; Korgel, B. A. In Vivo Whole Animal Fluorescence Imaging of 
A Microparticle-based Oral Vaccine Containing $\left(\mathrm{CuInSe}_{\mathrm{x}} \mathrm{S}_{2-\mathrm{x}}\right) / \mathrm{ZnS}$ Core/Shell Quantum Dots. Nano Lett. 2013, 13, 4294-4298.

(8) Ji, S.; Shi, T.; Qiu, X.; Zhang, J.; Xu, G.; Chen, C.; Jiang, Z.; Ye, C. A Route to Phase Controllable $\mathrm{Cu}_{2} \mathrm{ZnSn}\left(\mathrm{S}_{1-\mathrm{x}} \mathrm{Se}_{\mathrm{x}}\right)_{4}$ Nanocrystals with Tunable Energy Bands. Sci. Rep. 2013, 3, 2733.

(9) Bag, S.; Gunawan, O.; Gokmen, T.; Zhu, Y.; Mitzi, D. B. Hydrazine-Processed Ge-Substituted CZTSe Solar Cells. Chem. Mater. 2012, 24, 4588-4593.

(10) Yang, W.; Duan, H. S.; Cha, K. C.; Hsu, C. J.; Hsu, W. C.; Zhou, H.; Bob, B.; Yang, Y. Molecular Solution Approach to Synthesize Electronic Quality $\mathrm{Cu}_{2} \mathrm{ZnSnS}_{4}$ Thin Films. J. Am. Chem. Soc. 2013, 135, 6915-6920.

(11) Kim, I.; Kim, K.; Oh, Y.; Woo, K.; Cao, G.; Jeong, S.; Moon, J. BandgapGraded $\mathrm{Cu}_{2} \mathrm{Zn}\left(\mathrm{Sn}_{1-\mathrm{x}} \mathrm{Ge}_{\mathrm{x}}\right) \mathrm{S}_{4}$ Thin-Film Solar Cells Derived from Metal Chalcogenide Complex Ligand Capped Nanocrystals. Chem. Mater. 2014, 26, 3957-3965.

(12) Wang, W.; Winkler, M. T.; Gunawan, O.; Gokmen, T.; Todorov, T. K.; Zhu, Y.; Mitzi, D. B. Device Characteristics of CZTSSe Thin-Film Solar Cells with $12.6 \%$ Efficiency. Adv. Energy Mater. 2014, 4, 1301465.

(13) Ibanez, M.; Zamani, R.; LaLonde, A.; Cadavid, D.; Li, W.; Shavel, A.; Arbiol, J.; Morante, J. R.; Gorsse, S.; Snyder, G. J.; Cabot, A. $\mathrm{Cu}_{2} \mathrm{ZnGeSe}_{4}$ Nanocrystals: Synthesis and Thermoelectric Properties. J. Am. Chem. Soc. 2012, 134, 4060-4063. 
(14) Ford, G. M.; Guo, Q.; Agrawal, R.; Hillhouse, H. W. Earth Abundant Element $\mathrm{Cu}_{2} \mathrm{Zn}\left(\mathrm{Sn}_{1-\mathrm{x}} \mathrm{Ge}_{\mathrm{x}}\right) \mathrm{S}_{4}$ Nanocrystals for Tunable Band Gap Solar Cells: $6.8 \%$ Efficient Device Fabrication. Chem. Mater. 2011, 23, 2626-2629.

(15) Tian, Q.; Huang, L.; Zhao, W.; Yang, Y.; Wang, G.; Pan, D. Metal Sulfide Precursor Aqueous Solutions for Fabrication of $\mathrm{Cu}_{2} \mathrm{ZnSn}(\mathrm{S}, \mathrm{Se})_{4}$ Thin Film Solar Cells. Green Chem. 2015, 17, 1269-1275.

(16) S. Y. Wei, Y. C. Liao, C. H. Hsu, C. H. Cai, W. C. Huang, M. C. Huang, C. H. Lai, Nano Energy 26(2016,)74-82.

(17) Jia, Q. X.; McCleskey, T. M.; Burrell, A. K.; Lin, Y.; Collis, G. E.; Wang, H.; Li, A. D.; Foltyn, S. R. Polymer-assisted Deposition of Metal-oxide Films. Nat. Mater. 2004, 3, 529-532.

(18) Zou, G. F.; Zhao, J.; Luo, H. M.; McCleskey, T. M.; Burrell, A. K.; Jia, Q. X. Polymer-assisted-deposition: A Chemical Solution Route for A Wide Range of Materials. Chem. Soc. Rev. 2013, 42, 439-449.

(19) Scragg, J. J.; Ericson, T.; Fontané, X.; Izquierdo-Roca, V.; Pérez-Rodríguez, A.; Kubart, T.; Edoff, M.; Platzer-Björkman, C. Rapid Annealing of Reactively Sputtered Precursors for $\mathrm{Cu}_{2} \mathrm{ZnSnS}_{4}$ Solar Cells. Prog. Photovolt: Res. Appl. 2014, 22, 10-17.

(20) Sun, Y.; Zhang, Y.; Wang, H.; Xie, M.; Zong, K.; Zheng, H.; Shu, Y.; Liu, J.; Yan, H.; Zhu, M.; Lau, W. Novel Non-hydrazine Solution Processing of Earth- 
Abundant $\mathrm{Cu}_{2} \mathrm{ZnSn}(\mathrm{S}, \mathrm{Se})_{4}$ Absorbers for Thin-film Solar Cells. J. Mater. Chem. A 2013, 1, 6880-6887.

(21) Yang, W. C.; Miskin, C. K.; Carter, N. J.; Agrawal, R.; Stach, E. A. Compositional Inhomogeneity of Multinary Semiconductor Nanoparticles: A Case Study of $\mathrm{Cu}_{2} \mathrm{ZnSnS}_{4}$. Chem. Mater. 2014, 26, 6955-6962.

(22) Wang, G.; Zhao, W.; Cui, Y.; Tian, Q.; Gao, S.; Huang, L.; Pan, D. Fabrication of $\mathrm{A} \mathrm{Cu}_{2} \mathrm{ZnSn}(\mathrm{S}, \mathrm{Se})_{4}$ Photovoltaic Device by A Low-toxicity Ethanol Solution Process. ACS Appl. Mater. Interfaces 2013, 5, 10042-10047.

(23) Tan, J. M.; Lee, Y. H.; Pedireddy, S.; Baikie, T.; Ling, X. Y.; Wong, L. H. Understanding The Synthetic Pathway of A Single-phase Quarternary Semiconductor Using Surface-enhanced Raman Scattering: A Case of Wurtzite $\mathrm{Cu}_{2} \mathrm{ZnSnS}_{4}$ nanoparticles. J. Am. Chem. Soc. 2014, 136 18, 6684-6692.

(24) Altamura, G.; Vidal, J. Impact of Minor Phases on the Performances of CZTSSe Thin Film Solar Cells. Chem. Mater. 2016, 28, 3540-3563.

(25) Martin, T. R.; Katahara, J. K.; Bucherl, C. N.; Krueger, B. W.; Hillhouse, H. W.; Luscombe, C. K. Nanoparticle Ligands and Pyrolized Graphitic Carbon in CZTSSe Photovoltaic Devices. Chem. Mater. 2016, 28, 135-145.

(26) Kumar, M.; Dubey, A.; Adhikari, N.; Venkatesan, S.; Qiao, Q. Strategic Review of Secondary Phases, Defects and Defect-complexes in Kesterite CZTSSe Solar Cells. Energy Environ. Sci. 2015, 8, 3134-3159. 
(27) Khadka, D. B.; Kim, J. Study of Structural and Optical Properties of Kesterite $\mathrm{Cu}_{2} \mathrm{ZnGeX}_{4}(\mathrm{X}=\mathrm{S}, \mathrm{Se})$ Thin Films Synthesized by Chemical Spray Pyrolysis. Cryst. Eng. Comm. 2013, 15, 10500.

(28) Singh, A.; Coughlan, C.; Milliron, D. J.; Ryan, K. M. Solution Synthesis and Assembly of Wurtzite-Derived $\mathrm{Cu}-\mathrm{In}-\mathrm{Zn}-\mathrm{S}$ Nanorods with Tunable Composition and Band Gap. Chem. Mater. 2015, 27, 1517-1523.

(29) Ahmed, S.; Reuter, K. B.; Gunawan, O.; Guo, L.; Romankiw, L. T.; Deligianni, H. A High Efficiency Electrodeposited $\mathrm{Cu}_{2} \mathrm{ZnSnS}_{4}$ Solar Cell. Adv. Energy Mater. 2012, 2, 253-259.

(30) Cao, Y.; Denny, M. S., Jr.; Caspar, J. V.; Farneth, W. E.; Guo, Q.; Ionkin, A. S.; Johnson, L. K.; Lu, M.; Malajovich, I.; Radu, D.; Rosenfeld, H. D.; Choudhury, K. R.; Wu, W. High-Efficiency Solution-Processed $\mathrm{Cu}_{2} \mathrm{ZnSn}(\mathrm{S}, \mathrm{Se})_{4}$ Thin-film Solar Cells Prepared from Binary and Ternary Nanoparticles. J. Am. Chem. Soc. 2012, 134, 15644-15647.

(31) Singh, A.; Singh, S.; Levcenko, S.; Unold, T.; Laffir, F.; Ryan, K. M. Compositionally Tunable Photoluminescence Emission in $\mathrm{Cu}_{2} \mathrm{ZnSn}\left(\mathrm{S}_{1-\mathrm{x}} \mathrm{Se}_{\mathrm{x}}\right)_{4}$ Nanocrystals. Angew. Chem. Int. Ed. 2013, 52, 9120-9124.

(32) Fan, F. J.; Wu, L.; Gong, M.; Liu, G.; Wang, Y. X.; Yu, S. H.; Chen, S.; Wang, L. W.; Gong, X. G. Composition and Band-gap-tunable Synthesis of Wurtzitederived $\mathrm{Cu}_{2} \mathrm{ZnSn}\left(\mathrm{S}_{1-\mathrm{x}} \mathrm{Se}_{\mathrm{x}}\right)_{4} \quad$ Nanocrystals: Theoretical and Experimental Insights. ACS Nano 2013, 7, 1454-1463. 
(33) Zong, K.; Lu, S.; Wang, H.; Sun, Y.; Zheng, H.; Liu, J.; Yan, H. Retracted Article: The Synthesis of $\mathrm{Cu}_{2} \mathrm{Zn}\left(\mathrm{Ge}_{\mathrm{x}} \mathrm{Sn}_{1-\mathrm{x}}\right) \mathrm{Se}_{4}$ Nanocrystals with Tunable Band Gaps. Cryst. Eng. Comm. 2013, 15, 6942.

(34) Zhao, W. G.; Pan, D. C.; Liu, S. F. Kesterite $\mathrm{Cu}_{2} \mathrm{Zn}(\mathrm{Sn}, \mathrm{Ge})(\mathrm{S}, \mathrm{Se})_{4}$ Thin Film with Controlled Ge-doping for Photovoltaic Application. Nanoscale 2016, 8, 10160-10165.

(35) Liu, F.; Li, Y.; Zhang, K.; Wang, B.; Yan, C.; Lai, Y.; Zhang, Z.; Li, J.; Liu, Y. In Situ Growth of $\mathrm{Cu}_{2} \mathrm{ZnSnS}_{4}$ Thin Films by Reactive Magnetron Cosputtering. Sol. Energy Mater. Sol. Cells 2010, 94, 2431-2434.

(36) Scragg, J. J.; Dale, P. J.; Peter L. M. Towards Sustainable Materials for Solar Energy Conversion: Preparation and Photoelectrochemical Characterization of $\mathrm{Cu}_{2} \mathrm{ZnSnS}_{4}$. Electrochem. Commun. 2008, 10, 639-642.

(37) Nakayama, N.; Ito K. Sprayed Films of Stannite $\mathrm{Cu}_{2} \mathrm{ZnSnS}_{4}$. Appl. Surface Sci. 1996, 92, 171-175.

(38) Tanaka, T.; Nagatomo, T.; Kawasaki, D.; Nishio, M.; Guo, Q.; Wakahara, A.; Yoshida, A.; Ogawa, H. Preparation of $\mathrm{Cu}_{2} \mathrm{ZnSnS}_{4}$ Thin Films by Hybrid Sputtering. J. Phys. Chem. Solids 2005, 66, 1978-1981.

(39) Guo, Q.; Hillhouse, H. W.; Agrawal, R. Synthesis of $\mathrm{Cu}_{2} \mathrm{ZnSnS}_{4}$ Nanocrystal Ink and Its Use for Solar Cells. J. Am. Chem. Soc. 2009, 131, 11672-11673. 
(40) Carrete, A.; Shavel, A.; Fontane, X.; Montserrat, J.; Fan, J.; Ibanez, M.; Saucedo, E.; Perez-Rodriguez, A.; Cabot, A. Antimony-based Ligand Exchange to Promote Crystallization in Spray-Deposited $\mathrm{Cu}_{2} \mathrm{ZnSnSe}_{4}$ Solar Cells. J. Am. Chem. Soc. 2013, 135, 15982-15985.

(41) Zhou, H. P.; Duan, H. S.; Yang W. B.; Chen, Q.; Hsu, C. J.; Hsu, W. C.; Chen, C. C.; Yang, Y. Facial Single-component Precursor for $\mathrm{Cu}_{2} \mathrm{ZnSnS}_{4}$ with Enhanced Phase and Composition Controllability. Energy Environ. Sci. 2014, 7, 998-1005.

(42) Ki, W.; Hillhouse, H. W. Earth-abundant Element Photocoltaics Directly from Soluble Precursors with High Yield Using a Non-toxic Solvent. Adv. Energy Mater. 2011, 1, 732-735.

(43) Embden, J. V.; Chesman, A. S. R.; Gaspera, E. D.; Duffy, N. W.; Watkins, S. E.; Jasieniakvan, J. J. CuZnSnS ${ }_{4 x} \mathrm{Se}_{4(1-\mathrm{x})}$ solar cells from polar nanocrystal inks. J. Am. Chem. Soc. 2014, 136, 5237-5240. 


\section{TOC GRAPHIC}

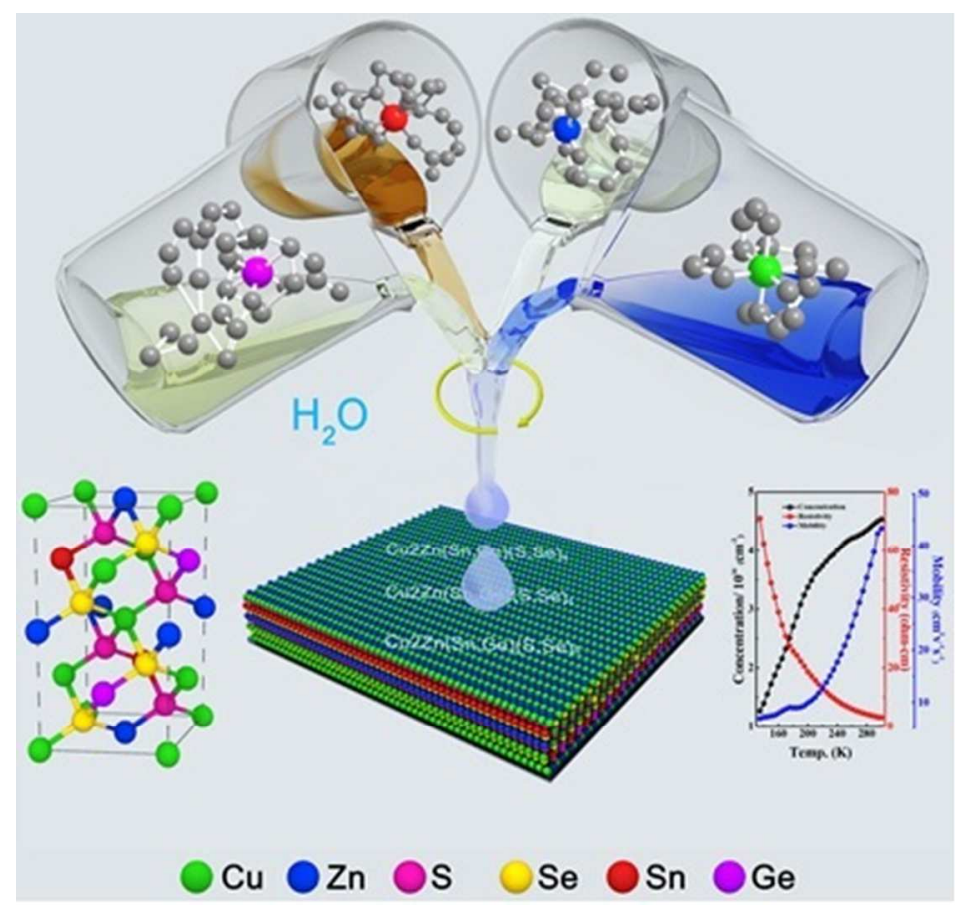

